\title{
El papel de la percepción en el yeísmo: Estudio preliminar con jueces catalanohablantes
}

\author{
Assumpció Rost Bagudanch \\ Universitat de les Illes Balears \\ assumpcio.rost@uib.es
}

Submitted: 10 de enero de 2014. Accepted: 15 de abril de 2014. Available on line: 16 de Febrero de 2015

Citation / Cómo citar este artículo: Rost Bagudanch, A. (2014). El papel de la percepción en el yeísmo: Estudio preliminar con jueces catalanohablantes. Loquens, 1(2), e010. doi: http://dx.doi.org/10.3989/loquens.2014.010

RESUMEN: El fenómeno del yeísmo se ha abordado desde varias perspectivas pero se ha tratado muy poco el papel que desempeña el oyente en él. Como proceso de cambio en marcha, el receptor de la señal ha de tener necesariamente un papel esencial que permita esclarecer cómo se empezó a propagar la innovación yeísta. Con este propósito, se ha decidido llevar a cabo un estudio perceptivo que permita averiguar si $[K]$ y $[j]$ pueden resultar ambiguos desde el punto de vista del receptor de la señal.

Sin embargo, la investigación de esta neutralización topa con una complicación inevitable: el avance de la innovación hace que sea difícil dar con hablantes que mantengan la distinción fonológica. Por este motivo, se ha acudido a la gramática comparada; es decir, se ha acudido a 20 jueces catalanohablantes que, en su L1, conservan la categoría $/ K /$ tal como en origen hizo el español. A estos jueces se les han administrado tres pruebas: una de ellas funcionaba como test de control y las otras dos, a partir de estímulos de locutores castellanohablantes distinguidores y yeístas, debían servir para averiguar si el cambio se puede achacar a problemas en la segmentación de la señal o a su recepción.

Los resultados indican que un $30 \%$ de los estímulos en las pruebas realizadas con input del español constituyen casos de confusión, que viene favorecida, además, por la presencia del segmento objeto de atención en sílaba átona y en contacto con vocales palatales.

Palabras clave: percepción fonética; yeísmo; fonética del español; cambio fónico.

ABSTRACT: The role of perception in yeísmo: A preliminary study with Catalan-speaking listeners.-Yeísmo, as a change in progress in the Spanish phonological system, has been studied from various perspectives, especially from dialectology and articulatory phonetics. However, the role of the listener in its origins and spread has been scarcely analysed. In fact, it is necessary to focus on the side of the listener to detect if the articulatory similarity of sounds $[K]$ and [j] can be perceptively ambiguous and, thus, confounded. The present work wants to examine this topic in order to determine how the innovative neutralization could initiate. With this purpose we have carried out a perception study which consisted of three different tests: the first one worked as control test and the other two were used to find out if the change could be related to signal reception problems or to opacities in the input segmentation. In these experiments, we have used samples from a Spanish speaker who upholded $/ K /$ and $/ \mathrm{j} /$ distinction (second test) and from a yeista speaker (third test).

Despite our concern is to analyse the dephonologization of $/ K /$ in Spanish, there is an important obstacle to achieve our goal: it is quite difficult to find Spanish speakers that do preserve the phonological distinction between $/ \mathrm{K} /$ and $/ \mathrm{j} /$ in the same way Spanish system once did. Therefore, we must rely on compared grammar: the judges of the perception tests were 20 Catalan speakers, a language that keeps this phonological contrast.

The results display that $30 \%$ of the stimulus from Spanish speakers were misinterpreted. In addition, data suggest that the presence of an adjacent palatal vowel and the occurrence in an unstressed position may favour the confusion and, hence, the recategorization process.

Keywords: speech perception; yeísmo; Spanish phonetics; sound change. 


\section{INTRODUCCIÓN ${ }^{1}$}

El yeísmo, como fenómeno de neutralización entre $[K]$ y [j] $]^{2}$ en favor de esta última opción (cf. Quilis, 1999, p. 315), ha sido objeto de atención desde perspectivas muy diversas, aunque tradicionalmente ha venido siendo estudiado desde el ámbito de la dialectología (cf. Gómez y Molina Martos, 2013, para un ejemplo reciente). En esta disciplina se ha tendido a tratar básicamente dos cuestiones: su extensión geográfica ${ }^{3}$ y la descripción, más o menos detallada, de las formas en que se puede dar ${ }^{4}$. Obviamente, la fonética y la fonología tienen mucho que aportar tanto en este último aspecto como en las implicaciones que este cambio en marcha tiene en el sistema lingüístico. Por supuesto, también se ha abordado el fenómeno desde estas disciplinas, especialmente en lo que a la producción fónica se refiere y, particularmente, lo tocante a la articulación de las diferentes realizaciones que puede presentar ${ }^{5}$.

La bibliografía existente abunda en la idea de que la confusión yeísta se origina por la semejanza articulatoria entre el sonido lateral palatal y el etiquetado tradicionalmente como fricativo mediopalatal, que parece corresponderse, al menos en la variedad más estándar del español, con una consonante aproximante palatal. De hecho, comúnmente, el rasgo que se emplea para oponerlos es la existencia de contacto o no entre los articuladores activo (lengua) y pasivo (paladar o prepaladar, según las fuentes). Así, se argumenta que, en términos de esfuerzo, resulta mucho más "sencilla" la articulación de [j] que la de $[K]$, puesto que el nivel de constricción necesario es mucho menor. Por otra parte, hay trabajos que han sugerido la semejanza acústica entre ambas realizaciones ${ }^{6}$, lo que podría contribuir a consolidar esta idea: se puede obtener una señal acústica determinada por medio de movimientos articulatorios diversos, por lo que no sería descabellado pensar que, ante varias posibilidades de producción que aseguran un mismo resultado, los hablantes opten por aquella que les suponga un menor esfuerzo motoro ${ }^{7}$. De hecho, autores clásicos como Alcina
Franch y Blecua (1975, pp. 374-375) o, más indirectamente, Alarcos Llorach (1965) emplean el argumento articulatorio para reforzar la idea de que la desaparición de la lateral palatal es lógica para la estabilidad del sistema, puesto que, de esta manera, se elimina una oposición no funcional.

No obstante, quedan algunos interrogantes abiertos respecto a la confusión yeísta. Se ha dicho que la razón del cambio es precisamente la tendencia a la relajación, a la facilidad en la producción; sin embargo, focalizar la atención en este aspecto no tiene en cuenta uno de los elementos clave de cualquier cambio: el papel que pueda tener el receptor de la señal. Autores como Ohala (1981, 1996, 2012) o Lindblom (1990a, 1990b) señalan que el eje central de las alteraciones en los sistemas hay que buscarlo en el oyente, que es quien percibe el input, lo procesa y lo interpreta de acuerdo con las restricciones propias de su sistema. Si los estímulos recibidos se adecuan a las categorías fonológicas previamente establecidas en su competencia lingüística, no se produce conflicto pero sí lo hay si esos estímulos no se identifican correctamente ${ }^{8}$. De hecho, Flemming (2004), al exponer las ideas básicas de la Teoría de la Dispersión de Contraste, define la percepción como el hecho de segmentar la señal y categorizar los segmentos en un conjunto de categorías. Los indicios necesarios para poder realizar esta tarea se dan por oposición a otros sonidos, aunque esta oposición no siempre resulta nítida porque está supeditada, por un lado, a la necesidad de maximizar la distintividad (esencial para asegurar la comunicación) y, por otro, a la de minimizar el esfuerzo en la producción, aspecto este en el que el contexto de aparición del sonido tiene una influencia importante. En esencia, indica que los contrastes pueden ser complicados de detectar porque las realizaciones con menor esfuerzo de una determinada categoría pueden resultar similares a las de otro elemento que contraste con ella.

En el yeísmo, según Moreno Fernández (2004, pp. 984-985), se parte de una situación de distinción neta entre dos categorías fónicas para pasar a una segunda etapa

\footnotetext{
${ }^{1}$ Debo agradecer a colegas del grupo LIDIAGC de la Universitat de Girona y a mis amigos su generosidad al cederme su tiempo para realizar las pruebas de percepción. Sin ellos, este estudio no hubiera sido posible.

${ }^{2}$ Pese a que se han tenido muy en cuenta los criterios de Martínez Celdrán (2004) y Martínez Celdrán y Fernández Planas (2007, p. 62) en cuanto a la naturaleza articulatoria y acústica del elemento palatal no lateral, en este caso se ha optado por emplear los criterios de transcripción fonética del AFI, que posee un símbolo específico para la consonante aproximante palatal sonora, [j].

${ }^{3}$ Vid. Hernando Cuadrado (2001), Quesada Pacheco (2010) o Rost Bagudanch (2014) en una aproximación más típicamente dialectal, y Molina Martos (2006) o García Mouton y Molina Martos (2012) desde una perspectiva sociolingüística. Para una referencia clásica, véase Navarro Tomás (1964).

${ }^{4}$ Para la problemática a que puede dar lugar la clasificación de los diversos alófonos detectados para este fenómeno, cf. Coloma (2012) o Rost Bagudanch (2013).

${ }^{5}$ Cf. Fernández Trinidad (2010), Martínez Celdrán y Fernández Planas (2002) o Quilis (1999, p. 315 y ss).

${ }^{6}$ La Real Academia Española (2011) señala que «el proceso es explicable por la cercanía articulatoria, acústica y perceptiva de estos sonidos, ya que ambos son palatales sonoros» (p. 220). Cf., además, Rost Bagudanch (2011, pp. 184-185). De hecho, es complicado hallar descripciones comparativas entre ambos sonidos en la bibliografía; en lengua española, lo más parecido a ello es Quilis (1999), que ofrece la caracterización acústica de [j] (p. 261), y, en páginas posteriores, la de $[\kappa]$ (pp. 312-314).

${ }^{7}$ Cf. Lindblom (1990a, p. 416).

${ }^{8}$ Siguiendo a Colantoni (2008), se pueden dar dos situaciones diferentes: o bien la señal se reinterpreta como una categoría fónica diferente a la del emisor pero existente en el sistema o bien se ha de crear una categoría nueva. Esta última opción se ha ilustrado en el aprendizaje de segundas lenguas: estímulos diferentes de los propios de la L1 no pueden identificarse con las categorías ya existentes (es lo que esta autora denomina "macrovariación").
} 
caracterizada por la variación y en la que se detectan realizaciones alofónicas comunes a ambas categorías (en concreto, [j]). La tercera etapa supondría la neutralización efectiva de $[K]$ en favor de distintas soluciones con mayor o menor grado de fricción pero ya sin rasgo de lateralidad. En consecuencia, podríamos inferir que, en algún momento, estos estímulos dejaron de ser perceptivamente diáfanos para el receptor, que fue incapaz de discriminarlos, tal como había sucedido en la primera fase, la de distinción. Desde este punto de vista, resulta justificado que se quiera analizar la importancia de la percepción en este fenómeno. Esta es, en realidad, la finalidad de este trabajo.

En efecto, aquí se quiere comprobar si existen diferencias perceptivas claras entre $[K]$ y $[\mathrm{j}]$ que puedan explicar, desde otro ángulo, las razones que llevan a la pérdida de la oposición. Articulatoriamente, sabemos que las hay'; acústicamente, no resulta tan claro, pero perceptivamente no tenemos datos: hay que analizar, como objetivo primordial, si los dos fonos en competencia se discriminan netamente o si se da confusión en el nivel perceptivo. Para ello, se van a realizar tres test de percepción con jueces que conserven la distinción. Precisamente en este punto hay que tener en cuenta un problema metodológico: ¿cómo hacerlo si se admite, bastante abiertamente, que el español ya no distingue $?^{10}$ Ante la falta de disponibilidad de hablantes hispanohablantes distinguidores, la respuesta hay que buscarla en la gramática comparada, en este caso, en hablantes de un sistema muy cercano que sí mantiene la oposición: el catalán.

En cualquier caso, la hipótesis de partida es que la distinción entre lateral palatal y aproximante palatal no va a resultar clara sino que se van a poder detectar errores, fruto de la confusión entre los estímulos. En este sentido, en la línea de Blevins (2004), se defiende que el cambio fonológico se ha desencadenado, en primera instancia, por errores de percepción que pueden llevar a ambigüedades en la interpretación fonológica de la señal, lo que implicaría un reanálisis a nivel fonológico $\mathrm{y}$, en consecuencia, la alteración del sistema.

El trabajo que presentamos, y que no supone más que una primera aproximación a esta cuestión, se organiza en cuatro partes. En primer lugar, se da cuenta del diseño de los test de percepción que se han administrado. A continuación, se exponen los resultados obtenidos, que se explican brevemente. La cuarta parte corresponde a la discusión de los mismos y se finaliza con la presentación de las conclusiones.

\section{DISEÑO EXPERIMENTAL}

El estudio perceptivo se ha llevado a cabo a partir de tres pruebas, todas ellas de identificación y de respuesta cerrada, elaboradas con el programa Praat (v. 5.3.74). En todas ellas el procedimiento de obtención de los estímulos fue el mismo: estos se extrajeron de grabaciones de habla espontánea, de una hora de duración aproximadamente, realizadas con una grabadora Olympus LS-10. Para cada prueba se acudió a un tipo de locutor diferente (catalanohablante, castellanohablante distinguidor y castellanohablante yeísta), como se detallará más abajo. En todos los test los estímulos consistían en secuencias [V V] que se habían segmentado de palabras que habían aparecido naturalmente en el discurso y que contenían las consonantes que interesaba analizar, a saber, $/ 1 /, / K / \mathrm{y} / \mathrm{j} /$ (en función de la prueba), en voces como zulo, cale, bombilla, bachillerato, apoyos o mayo ${ }^{11}$. Se procuró, hasta donde fue posible, que las secuencias resultantes no tuvieran sentido lógico para que la asociación con la semántica no influyera a la hora de identificar los estímulos.

A los jueces se les indicó que iban a escuchar una serie de estímulos formados por una secuencia [VCV] y que, después de oír tres veces cada estímulo, debían decidir si la consonante se correspondía con $/ 1 /, / K / \mathrm{o} / \mathrm{j} /$ ( gún el test). Asimismo, se les explicó que no había respuestas correctas e incorrectas sino que se trataba de conocer cuál era su valoración acerca de la naturaleza de una serie de ejemplos. Se puso énfasis en que necesariamente había que elegir una opción y se les advirtió de que no debían intentar equilibrar las respuestas porque el número de casos no lo estaba. Estos se presentaron en orden aleatorio. Las pruebas se realizaron en un ordenador personal y se emplearon auriculares para asegurar la calidad de la exposición y el aislamiento respecto a otros sonidos.

Los 20 jueces a los que se recurrió eran catalanohablantes y tenían el catalán como L1. Todos ellos procedían de la zona de Girona, un área en la que, por regla general, el catalán mantiene la distinción entre $[K] \mathrm{y}[\mathrm{j}]^{12}$. $\mathrm{Su}$ edad se encontraba entre los 27 y los 45 años. Todos tenían educación superior; de hecho, habían cursado estudios relacionados con la lingüística o la filología, por lo que tenían conocimientos de fonética.

Las tres pruebas tenían finalidades distintas. La primera de ellas (prueba 1) sirvió de test de control para asegurar que los jueces fueran realmente distinguidores. En ella, los estímulos procedían de la grabación de un locu-

\footnotetext{
${ }^{9}$ Cf. Fernández Planas (2001), Martínez Celdrán y Fernández Planas (2007), Recasens y Espinosa (2006) o Recasens (2013), por ejemplo.

${ }^{10}$ Cf. Hualde (2005, p. 180), por ejemplo. Incluso la RAE (2011) insinúa que la distinción ha quedado relegada a ciertas áreas muy concretas: «en la mayor parte del dominio hispanohablante ha desaparecido la distinción fonológica entre la consonante lateral palatal / $/ / \mathrm{y}$ la fricativa palatal $/ \mathrm{j} / \gg$ (p. 194).

${ }^{11} \mathrm{La}$ lista completa de palabras utilizadas para la obtención de los estímulos en cada uno de los test aparece en el anexo al final del artículo.

${ }^{12}$ Recasens (1991) incluye el área de Girona dentro de las zonas en que se documenta yeísmo en catalán, si bien reconoce que «a l'àrea nord-occidental del Principat» este fenómeno es recesivo $(\S 16.3 .6 .1)$.
} 
tor catalanohablante que se expresaba en español. Se consiguieron términos en los que las consonantes que interesaba identificar respondían a las categorías fonológicas $/ 1 /, / K /$ y $/ \mathrm{j} / \mathrm{y}$ cuyas características acústicas respondían a las prototípicas para una lateral alveolar, una lateral palatal y una aproximante palatal ${ }^{13}$. Los casos se pudieron equilibrar en 11 para cada una de las mencionadas categorías. En consecuencia, en este test se ofrecían tres posibilidades de respuesta: $/ 1 /, / K / \mathrm{y} / \mathrm{j} /$.

En la segunda (prueba 2), el locutor era castellanohablante y netamente distinguidor: originario de un pueblo pequeño del este de la provincia de Salamanca, era plenamente consciente de que este rasgo de su habla lo diferenciaba de aquellos vecinos suyos que se habían trasladado a la capital, a Madrid. El procedimiento para obtener los estímulos fue análogo al del test de control pero, en esta ocasión, se decidió limitar la prueba a los segmentos objeto de estudio, es decir, los palatales. De la grabación se pudieron extraer 21 ejemplos claros de lateral palatal y seis de aproximante palatal. En esta ocasión, como es lógico, los jueces únicamente podían escoger entre dos respuestas posibles: $/ \mathrm{K} / \mathrm{o} / \mathrm{j} /$.

La tercera prueba (prueba 3 ) se planteó como contraste a la segunda. Se recurrió a un informante castellanohablante yeísta y, a partir de su grabación, se recogieron 26 casos de aproximante palatal. En este caso, nuevamente, los jueces debían elegir entre dos categorías, $/ K / \mathrm{o} / \mathrm{j} /$. En la Tabla 1 se ofrece un resumen de los casos y del procedimiento empleado para cada prueba.

Tabla 1. Resumen del número de estímulos y del procedimiento empleado en cada una de las pruebas practicadas.

\begin{tabular}{|l|c|c|c|c|}
\hline \multicolumn{2}{|c|}{} & Prueba 1 & Prueba 2 & Prueba 3 \\
\hline \multirow{2}{*}{$\begin{array}{l}\text { n. } \\
\text { casos }\end{array}$} & 1 & 11 & - & - \\
\cline { 2 - 5 } & $\kappa$ & 11 & 21 & - \\
\cline { 2 - 5 } & $\mathrm{j}$ & 11 & 6 & 26 \\
\hline $\begin{array}{l}\text { L1 del } \\
\text { locutor }\end{array}$ & catalán & $\begin{array}{c}\text { español } \\
\text { distinguidor }\end{array}$ & $\begin{array}{c}\text { español } \\
\text { yeísta }\end{array}$ \\
\hline respuestas & 3 opciones & 2 opciones & 2 opciones \\
\hline
\end{tabular}

Por otra parte, en las pruebas 2 y 3 también interesaba comprobar si los posibles casos de confusión podían relacionarse con factores de tipo contextual, especialmente el acento y el tipo de vocal precedente y siguiente. Como es lógico atendiendo al tipo de corpus del que se han obtenido los estímulos, la distribución de las ocurrencias no está equilibrada en función de estas variables. El número de casos obtenidos globalmente se reproduce en la Tabla 2.

El análisis de los datos se ha efectuado con el programa SPSS (v. 15). Se han utilizado tablas de contingencia a partir de las cuales se ha recurrido a pruebas de $\chi^{2}$, test $V$ de Cramer y $\tau$ de Kendall para determinar la existencia de relación entre las variables tomadas en consideración así como el tipo de relación que se establecía entre ellas.

Tabla 2. Número de casos totales estudiados para cada uno de los factores contextuales tomados en consideración en las pruebas 2 y 3 .

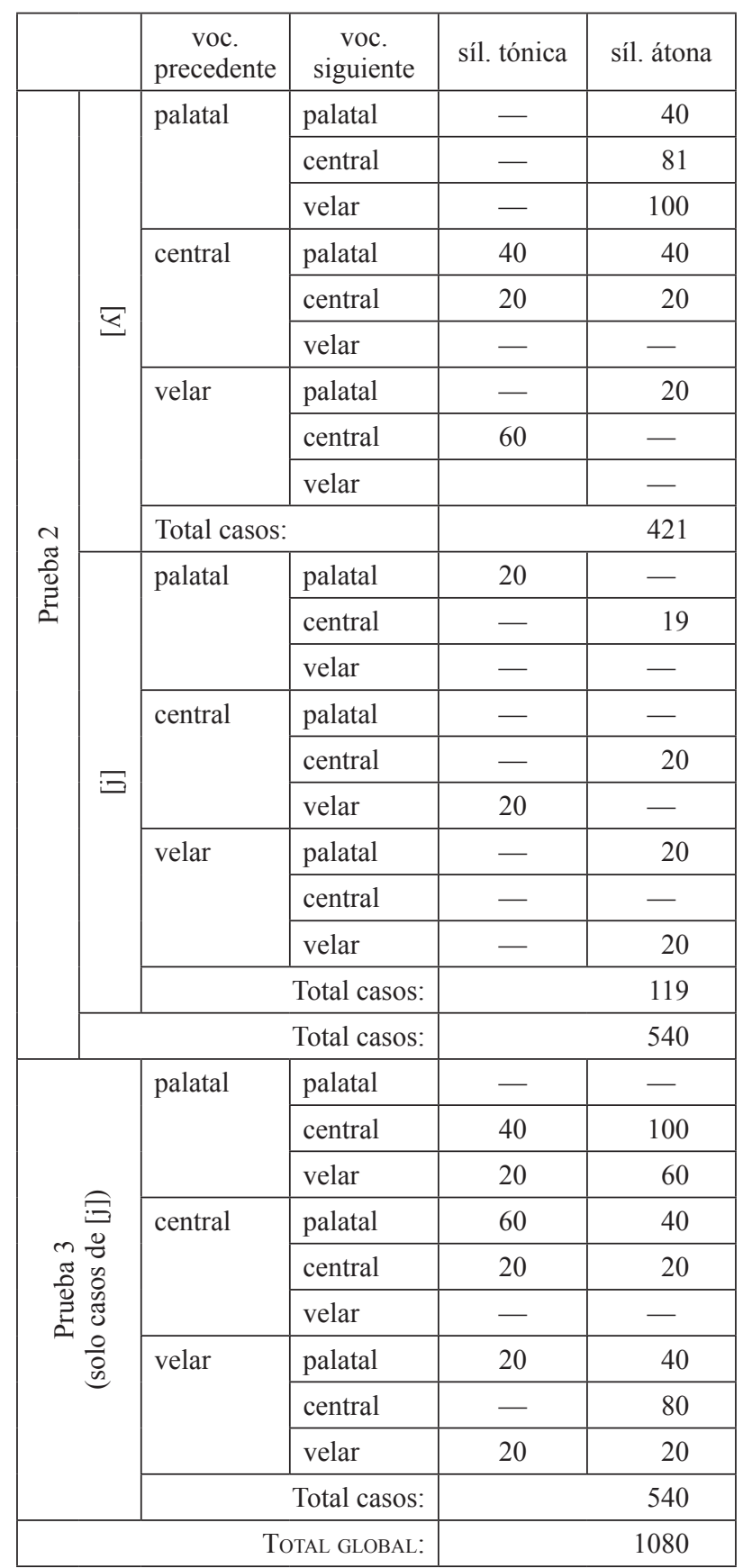

${ }^{13}$ Cf. Recasens (1991, p. 317) para una caracterización de la lateral palatal comparada con la aproximante palatal. Para una caracterización de estas consonantes en español, vid. Martínez Celdrán y Fernández Planas (2007, pp. 59, 136-141), Quilis (1999, pp. 261, 312-314) o Quilis, Esgueva, Gutiérrez Araus y Cantarero (1979). Véase también Ladefoged y Maddieson (1996, pp. 189, 193-194). 


\section{RESULTADOS}

Para conseguir mayor claridad expositiva, se ha decidido presentar los resultados de cada una de las pruebas por separado.

\subsection{Prueba 1}

Como ya se ha mencionado, el test de control ha hecho posible comprobar que los jueces eran perfectamente capaces de discriminar entre $[K]$ y $[\mathrm{j}]$. En la matriz de confusión y en el gráfico de la Figura 1, se advierte que más del $90 \%$ de las respuestas coinciden con los resultados esperados. De hecho, según la valoración de la prueba hecha por los encuestados, esta no ofrece ninguna dificultad y las respuestas son inmediatas, sin vacilación.

Figura 1. Matriz de confusión y gráfico de barras obtenidos con los datos correspondientes a la prueba 1. La categoría percibida aparece en las columnas, mientras que la realización fonética lo hace en las filas. Se han sombreado las identificaciones exitosas.

\begin{tabular}{|c|c|c|c|c|c|}
\hline & \multicolumn{3}{|c|}{ categoría percibida } & \multirow{2}{*}{$\begin{array}{l}\text { n. }{ }^{\circ} \\
\text { casos }\end{array}$} \\
\hline & & /1/ & $/ \Lambda /$ & $/ \mathrm{j} /$ & \\
\hline \multirow{3}{*}{ 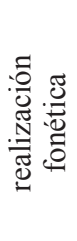 } & [1] & $\begin{array}{r}207 \\
94,1 \%\end{array}$ & $\begin{array}{r}4 \\
1,8 \%\end{array}$ & $\begin{array}{r}9 \\
4,1 \%\end{array}$ & 220 \\
\hline & {$[\kappa]$} & $\begin{array}{r}7 \\
3,2 \%\end{array}$ & $\begin{array}{r}204 \\
92,7 \%\end{array}$ & $\begin{array}{r}9 \\
4,1 \%\end{array}$ & 220 \\
\hline & [j] & $\begin{array}{r}6 \\
2,7 \%\end{array}$ & $\begin{array}{r}11 \\
5,0 \%\end{array}$ & $\begin{array}{r}203 \\
92,3 \%\end{array}$ & 220 \\
\hline
\end{tabular}

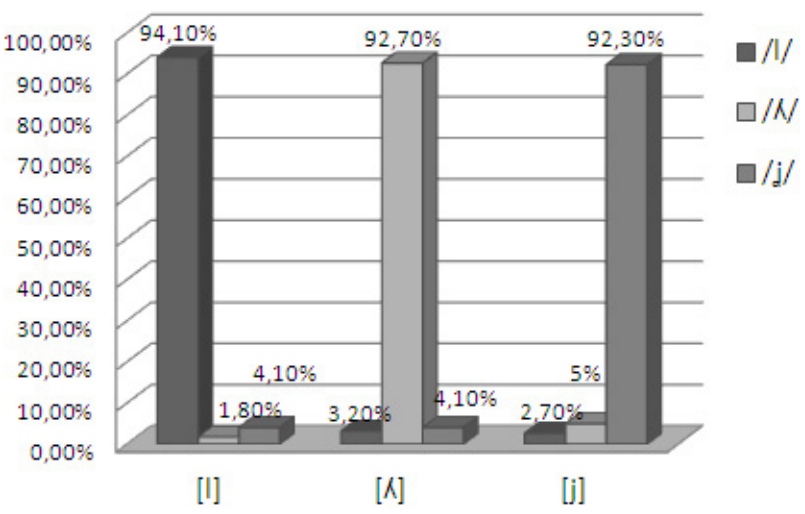

El cálculo de la distancia perceptiva ${ }^{14}$ establece que se trata de tres elementos claramente diferenciados, aunque se observa que la distancia perceptiva resulta menor entre $/ \mathrm{K} / \mathrm{y} / \mathrm{j} /(3,803)$ respecto a los binomios $/ 1 /-/ K /(4.414)$ y $/ 1 /-/ \mathrm{j} /(4,104)$ (cf. Tabla 3$)$; es decir, a tenor de las respuestas obtenidas, $/ K / \mathrm{y} / \mathrm{j} /$ son más semejantes.
Tabla 3. Valores del cálculo de similitudes y de distancia perceptiva entre las categorías fónicas posibles en la prueba 1.

\begin{tabular}{|l|c|c|}
\hline & similitud & distancia perceptiva \\
\hline$/ 1 /-/ K /$ & 0,0121 & 4,414 \\
\hline$/ 1 /-/ \mathrm{j} /$ & 0,0165 & 4,104 \\
\hline$/ \mathrm{K} /-\mathrm{j} /$ & 0,0223 & 3,803 \\
\hline
\end{tabular}

Por otra parte, los resultados de la prueba de $\chi^{2}$ revelan que existe relación entre la categoría percibida y la realización fonética y, de hecho, $V$ de Cramer indica además que esta relación es muy fuerte $(V=0,896)^{15}$ y $\tau_{c}$ de Kendall, que se da una relación directa entre valores acústicos y perceptivos $\left(\tau_{c}=0,886\right)$ (cf. Tabla 4). Estos resultados vienen a demostrar que, en efecto, los jueces son perfectamente capaces de interpretar las realizaciones acústicas que actúan como input con la categoría perceptiva esperable en cada caso. Además, con estos datos se puede obtener una primera composición de lugar de la distancia perceptiva entre los elementos objeto de estudio en un sistema netamente distinguidor.

Tabla 4. Valores de los estadísticos aplicados para evaluar la relación entre realización fonética y categoría percibida.

\begin{tabular}{|l|c|c|}
\hline & valor & significación \\
\hline$\chi^{2}$ & 1059,02 & $<, 0001$ \\
\hline$V$ de Cramer & 0,896 & $<, 0001$ \\
\hline$\tau_{c}$ de Kendall & 0,886 & $<, 0001$ \\
\hline
\end{tabular}

\subsection{Prueba 2}

En la segunda prueba, como se recordará, los estímulos fueron producidos por un locutor castellanohablante distinguidor. En este caso, se encuentran segmentos que, mayoritariamente, corresponden al sonido lateral palatal junto con algunos de aproximante palatal.

Los resultados son aparentemente claros ya que apuntan a que los jueces han identificado correctamente el estímulo fonético con la categoría perceptiva esperada (cf. Figura 2). Sin embargo, es necesario notar que el nivel de errores ha aumentado respecto a la prueba 1: los aciertos en ningún caso superan el $75 \%$ (72\% para la lateral palatal y $69,7 \%$ para la aproximante).

El cálculo de la distancia perceptiva muestra que la lateral y la aproximante resultan más similares que en el test de control (1,89 en este frente a 3,80 en aquel), tal como puede comprobarse en la Tabla 5. Los resultados de los estadísticos indican que existe relación entre realización fonética y categoría percibida pero que esta relación es poco robusta $\left(V=0,358, \tau_{c}=0,287\right)($ cf. Tabla 6$)$.

\footnotetext{
${ }^{14}$ Cf. Johnson (2003, pp. 66-68) para la explicación de este tipo de cálculos.

${ }^{15} \mathrm{Se}$ considera que valores de $\mathrm{V}$ cercanos a 1 indican la existencia de una relación muy fuerte entre las variables, mientras que si estos se aproximan a 0 , dicha relación será débil.
} 
Figura 2. Matriz de confusión y gráfico de barras obtenidos con los datos de la prueba 2 . Las realizaciones fonéticas aparecen en las filas mientras que, en las columnas, figuran las categorías percibidas. Se han sombreado las identificaciones exitosas.

\begin{tabular}{|c|c|c|c|c|}
\hline & \multicolumn{2}{|c|}{ categoría percibida } & \multirow{2}{*}{ n. ${ }^{\circ}$ casos } \\
\hline & & $\mid K /$ & /j/ & \\
\hline \multirow{2}{*}{ 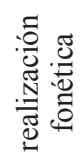 } & {$[\Lambda]$} & $\begin{array}{r}303 \\
72.0 \%\end{array}$ & $\begin{array}{r}118 \\
28.0 \%\end{array}$ & 421 \\
\hline & [j] & $\begin{array}{r}36 \\
30,3 \%\end{array}$ & $\begin{array}{r}83 \\
69,7 \%\end{array}$ & 119 \\
\hline
\end{tabular}

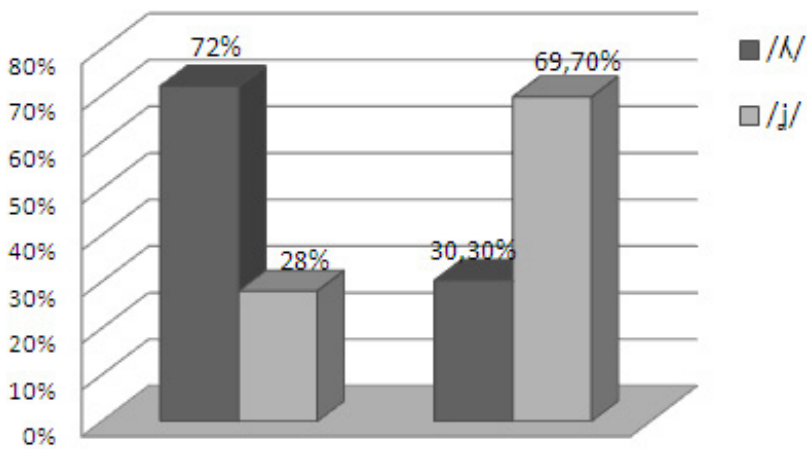

[ᄉ]

[j]

Tabla 5. Valores del cálculo de similitudes y de distancia perceptiva entre las categorías fónicas posibles y las realizaciones fonéticas en la prueba 2.

\begin{tabular}{|c|c|c|}
\hline & similitud & distancia perceptiva \\
\hline$/ K /-/ \mathrm{j} /$ & 0,151 & 1,890 \\
\hline
\end{tabular}

Tabla 6. Valores de los estadísticos aplicados para evaluar la relación entre realización fonética y categoría percibida en la prueba 2 .

\begin{tabular}{|l|c|c|}
\hline & valor & significación \\
\hline$\chi^{2}$ & 69,104 & $<, 0001$ \\
\hline$V$ de Cramer & 0,358 & $<, 0001$ \\
\hline$\tau_{c}$ de Kendall & 0,287 & $<, 0001$ \\
\hline
\end{tabular}

Los jueces, por lo tanto, son capaces de reconocer la diferencia entre lateral palatal y aproximante palatal pero el nivel de vacilación y de confusión es importante, ya que supone un $30 \%$ de las respuestas. La valoración que ellos mismos hacen de la prueba es que es complicada y que no resulta sencillo decidirse por una opción u otra.

\subsubsection{Influencia del acento}

De forma global, parece que la tasa de reconocimiento en sílaba átona y tónica está relativamente equilibrada (cf. Tabla 7); sin embargo, las pruebas de $\chi^{2}$ indican que sí hay relación entre la identificación de la señal y el acento $\left(\chi^{2}=22,465 ; g l=1 ; p<0,0001\right)$, aunque esta relación no sería muy robusta ( $V$ de Cramer $=0,375)$.

De hecho, el acento incidiría en el reconocimiento perceptivo del estímulo de forma más clara cuando este corresponde a una aproximante palatal: esta consonante se identifica mejor en contexto acentuado que en átono $(72,5 \%$ de los casos frente a $68,4 \%)$. En cambio, en $[\Lambda]$ el porcentaje global de aciertos es ligeramente mayor en contexto átono $(72,8 \%$ vs. $70 \%)$. Es interesante ver que, si nos fijamos en los valores porcentuales, se aprecia una cierta tendencia a identificar $/ \mathrm{j} /$ en posición tónica.

No obstante, al centrarnos únicamente en los errores se clarifica más la situación: el 69,4\% de las confusiones tanto en $[K]$ como en [j] se dan en sílaba átona y solo un tercio de ellos se produce en situación tónica, como puede observarse en la Figura 3.

Tabla 7. Número de casos de identificaciones exitosas en función del acento en la prueba 2. Se han sombreado los resultados predominantes.

\begin{tabular}{|c|c|c|c|c|}
\hline & \multicolumn{2}{|c|}{$[\Lambda]$} & \multicolumn{2}{|c|}{ [j] } \\
\hline & $\mid K /$ & $/ \mathrm{j} /$ & $/ \mathrm{j} /$ & $\mid K /$ \\
\hline síl. tónica & $\begin{array}{r}84 \\
(70 \%)\end{array}$ & $\begin{array}{r}36 \\
(30 \%)\end{array}$ & $\begin{array}{r}29 \\
(72,5 \%)\end{array}$ & $\begin{array}{r}11 \\
(27,5 \%)\end{array}$ \\
\hline síl. átona & $\begin{array}{r}219 \\
(72,8 \%)\end{array}$ & $\begin{array}{r}82 \\
(27,2 \%)\end{array}$ & $\begin{array}{r}54 \\
(68,4 \%)\end{array}$ & $\begin{array}{r}25 \\
(31,6 \%)\end{array}$ \\
\hline Total casos: & \multicolumn{2}{|c|}{421} & \multicolumn{2}{|c|}{119} \\
\hline
\end{tabular}

Figura 3. Gráfico de barras que muestra el porcentaje de errores de percepción en función del acento para $[K]$ y para [j] en la prueba 2 .

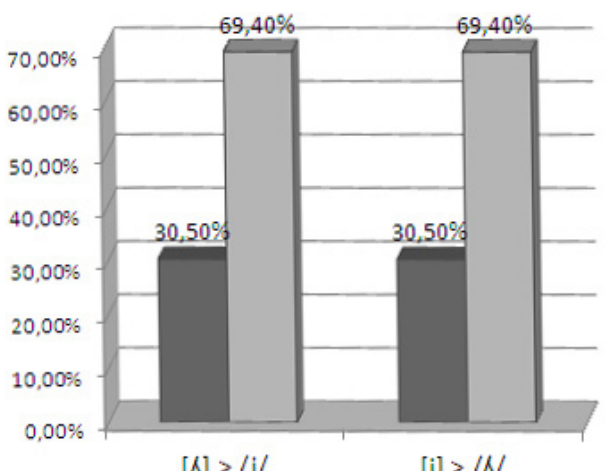

silaba tónica 口silaba átona

\subsubsection{Influencia de las vocales adyacentes}

$\mathrm{Al}$ analizar los errores de identificación en función del contexto vocálico precedente y siguiente, se han apreciado algunos comportamientos interesantes. Como se desprende de los datos incluidos en la Tabla 8, que recoge el número de confusiones dependiendo tanto de las vocales adyacentes como del acento, los errores más frecuentes se dan en contacto con vocales palatales. 
En efecto, la mayor parte de las confusiones se dan tras una vocal anterior, tanto en los casos de realización fonética lateral como aproximante y, además, los problemas de discriminación suelen aparecer en contexto átono. Invariablemente, el menor número de errores se da tras vocales velares.

Tabla 8. Número de casos de confusión de $[K]$ por $/ \mathrm{j} / \mathrm{y}$ de $[\mathrm{j}]$ por $/ K /$ en función del contexto vocálico y del acento. Se han sombreado los resultados predominantes. Los porcentajes se dan con relación al número global de errores.

\begin{tabular}{|c|c|c|c|c|}
\hline \multirow{2}{*}{ contexto } & \multicolumn{2}{|c|}{$[K] \mathrm{a} / \mathrm{j} /$} & \multicolumn{2}{|c|}{ [j] à $/ K /$} \\
\hline & s. tón. & s. át. & s. tón. & s. át. \\
\hline$\left[\mathrm{V}_{\mathrm{pal}}-\mathrm{V}_{\mathrm{pal}}\right]$ & - & 16 & 7 & - \\
\hline$\left[\mathrm{V}_{\mathrm{pal}}-\mathrm{V}_{\mathrm{centr}}\right]$ & - & 17 & - & 16 \\
\hline$\left[\mathrm{V}_{\mathrm{pal}}-\mathrm{V}_{\mathrm{vel}}\right]$ & - & 18 & - & - \\
\hline Total casos & \multicolumn{2}{|c|}{$51(43,22 \%)$} & \multicolumn{2}{|c|}{$23(63,88 \%)$} \\
\hline$\left[\mathrm{V}_{\text {centr }}-\mathrm{V}_{\text {pal }}\right]$ & 19 & 10 & - & - \\
\hline$\left[\mathrm{V}_{\text {centr }}-\mathrm{V}_{\text {centrt }}\right]$ & 4 & 14 & - & 6 \\
\hline$\left[\mathrm{V}_{\text {centr }}-\mathrm{V}_{\mathrm{vel}}\right]$ & - & - & 4 & - \\
\hline Total casos & \multicolumn{2}{|c|}{$47(39,83 \%)$} & \multicolumn{2}{|c|}{$10(27,02 \%)$} \\
\hline$\left[\mathrm{V}_{\left.\mathrm{vel}-\mathrm{V}_{\mathrm{pal}}\right]}\right]$ & 一 & 7 & - & 2 \\
\hline$\left[\mathrm{V}_{\mathrm{vel}-} \mathrm{V}_{\mathrm{centr}}\right]$ & 13 & - & - & - \\
\hline$\left[\mathrm{V}_{\mathrm{vel}-} \mathrm{V}_{\mathrm{vel}}\right]$ & - & - & - & 1 \\
\hline Total casos & \multicolumn{2}{|c|}{$20(16,94 \%)$} & \multicolumn{2}{|c|}{$3(8,10 \%)$} \\
\hline Total global & \multicolumn{2}{|c|}{$n=118 / 421$} & \multicolumn{2}{|c|}{$n=36 / 119$} \\
\hline
\end{tabular}

De todos modos, no hay que perder de vista que la realización acústica lateral palatal se confunde también, en un volumen importante de ocurrencias, tras vocal central; sin embargo, es importante notar que, de los 47 casos de errores tras [a], en 29 (más de la mitad) interviene una vocal palatal. Esto parece apuntar a que la presencia de un segmento vocálico palatal propiciaría los problemas en la discriminación.

Desde un punto de vista estadístico, las pruebas solo pueden aplicarse a parte de los contextos, puesto que, en algunos, no se puede establecer una comparación por falta de casos. Sin embargo, los resultados obtenidos permiten dar carta de naturaleza a algunas de las observaciones hechas de forma general hasta aquí (cf. Tabla 9): se demuestra que los contextos $\left[\mathrm{V}_{\mathrm{pal}-} \mathrm{V}_{\text {centr }}\right],\left[\mathrm{V}_{\text {centr }}-\mathrm{V}_{\text {centr }}\right] \mathrm{y}$ $\left[\begin{array}{ll}\mathrm{V}_{\mathrm{vel}} & \mathrm{V}_{\mathrm{pal}}\end{array}\right]$ en sílaba átona favorecen la confusión de forma muy clara, a tenor de los resultados de $V$ de Cramer. En el resto, como se ha comentado, o no existen ejemplos para poder aplicar los estadísticos o bien estos no resultan significativos.

\subsection{Prueba 3}

Por último, se administraron estímulos de un hablante castellanohablante yeísta, por lo que todos los estímulos incorporaban un elemento aproximante palatal. Sorprendentemente, la mayor parte de los jueces consideraron este test el más complicado de todos e indicaron no estar seguros de sus respuestas. Los resultados de la matriz de confusión reproducida en la Figura 4 ponen de manifiesto que prácticamente un $35 \%$ de los casos se ha reinterpretado como lateral palatal, de modo que un $65 \%$ de los estímulos se asocia con la categoría aproximante palatal.

Tabla 9. Valores de los estadísticos aplicados a los casos de confusión de la prueba 2 para evaluar la relación entre categoría fónica percibida, el contexto vocálico y el acento.

\begin{tabular}{|c|c|c|c|}
\hline contexto & estadístico & valor & sig. \\
\hline \multirow{3}{*}{$\begin{array}{l}{\left[\mathrm{i} / \mathrm{e} \_\mathrm{a}\right]} \\
* \text { acento }\end{array}$} & $\chi^{2}$ & 33,000 & $<, 0001$ \\
\hline & $V$ de Cramer & 1,000 & $<, 0001$ \\
\hline & $\tau_{c}$ Kendall & 0,999 & $<, 0001$ \\
\hline \multirow{3}{*}{$\begin{array}{l}{[\mathrm{a} \text { a }} \\
\text { *acento }\end{array}$} & $\chi^{2}$ & 20,000 & $<, 0001$ \\
\hline & $V$ de Cramer & 1,000 & $<, 0001$ \\
\hline & $\tau_{c}$ Kendall & 0,840 & $<, 0001$ \\
\hline \multirow{3}{*}{$\begin{array}{l}{\left[\mathrm{u} / \mathrm{o}_{-} \mathrm{i} / \mathrm{e}\right]} \\
\text { *acento }\end{array}$} & $\chi^{2}$ & 9,000 & $<, 003$ \\
\hline & $V$ de Cramer & 1,000 & $<, 0001$ \\
\hline & $\tau_{c}$ Kendall & 0,691 & $<, 0001$ \\
\hline
\end{tabular}

Figura 4. Matriz de confusión y gráfico de barras obtenidos con los resultados de la prueba 3 . En las columnas aparecen las categorías perceptivas y, en las filas, las realizaciones fonéticas. Se han sombreado las identificaciones exitosas.

\begin{tabular}{|l|c|c|c|c|}
\hline \multicolumn{2}{|c|}{} & \multicolumn{2}{|c|}{ categoría percibida } & \multirow{2}{*}{ n. ${ }^{\circ}$ casos } \\
\cline { 3 - 4 } \multicolumn{2}{|c|}{ input } & {$[\mathrm{K} /$} & $/ \mathrm{j} /$ & \\
\hline & & 181 & 339 & 520 \\
& $34,8 \%$ & $65,2 \%$ & \\
\hline
\end{tabular}

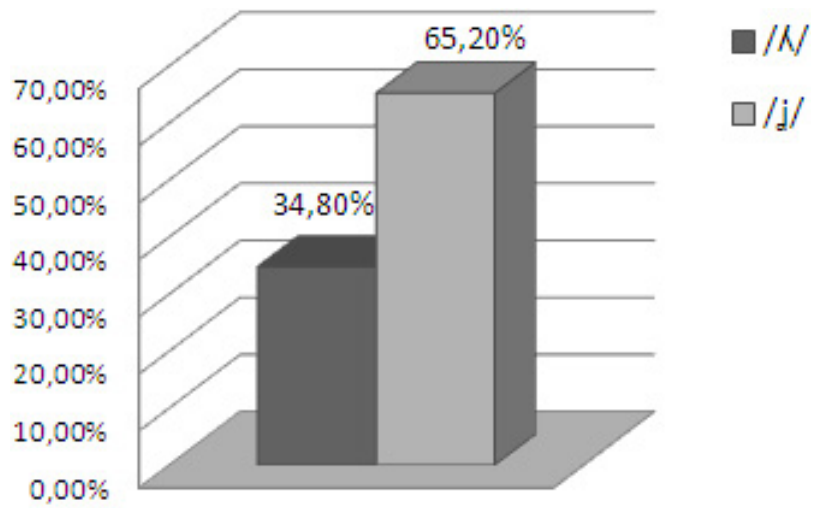

[j]

En vista de estos resultados se pensó que el hecho de haber proporcionado un solo tipo de estímulo pudo haber condicionado el resultado, por lo que se recurrió a una prueba complementaria. En ella se emplearon secuencias 
del mismo locutor yeísta pero, además de casos de [j], se incluyeron otros de $[K]$. Estos últimos, como es lógico, no podían corresponder a una categoría $/ K /$ dada la naturaleza no distinguidora del informante: procedían de ejemplos que, fonológicamente, se asocian a /li/ y en los que /1/ había sido palatalizada (en términos como caliente o alias, por ejemplo). Como estas falsas ocurrencias de lateral palatal se relacionan, en principio, con secuencias con $/ 1 /$, se optó por incluir tres posibles respuestas: /1/, / $/$ $\mathrm{y} / \mathrm{j} /$.

Los resultados no hacen más que confirmar los obtenidos en la prueba 3: un 32,5\% de los estímulos correspondientes a la aproximante palatal se identifican con $/ K /$ mientras que los aciertos se mantienen en un $65 \%$ (cf. la matriz de confusión de la Figura 5). Sin embargo, hay que tener en cuenta que un 2,6\% de los casos se han asociado a /1/, es decir, una categoría con rasgo [+lateral]. En cuanto a los casos de lateral palatal, se asocian mayoritariamente con /1/ (91\%).

Figura 5. Matriz de confusión y gráfico de barras obtenidos con los datos del experimento complementario. Se han sombreado las casillas comparables con la prueba 3.

\begin{tabular}{|c|c|c|c|c|c|}
\hline & \multicolumn{3}{|c|}{ categoría percibida } & \multirow{2}{*}{$\begin{array}{c}\text { n. }^{\circ} \\
\text { casos }\end{array}$} \\
\hline & & $/ 1 /$ & $\mid K /$ & $/ \mathrm{j} /$ & \\
\hline \multirow{2}{*}{ 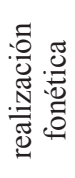 } & {$[\Lambda]$} & $\begin{array}{r}590 \\
91,3 \%\end{array}$ & $\begin{array}{r}26 \\
4,0 \%\end{array}$ & $\begin{array}{r}30 \\
4,6 \%\end{array}$ & 646 \\
\hline & [j] & $\begin{array}{r}15 \\
2,6 \%\end{array}$ & $\begin{array}{r}185 \\
32,5 \%\end{array}$ & $\begin{array}{r}370 \\
64,9 \%\end{array}$ & 570 \\
\hline
\end{tabular}

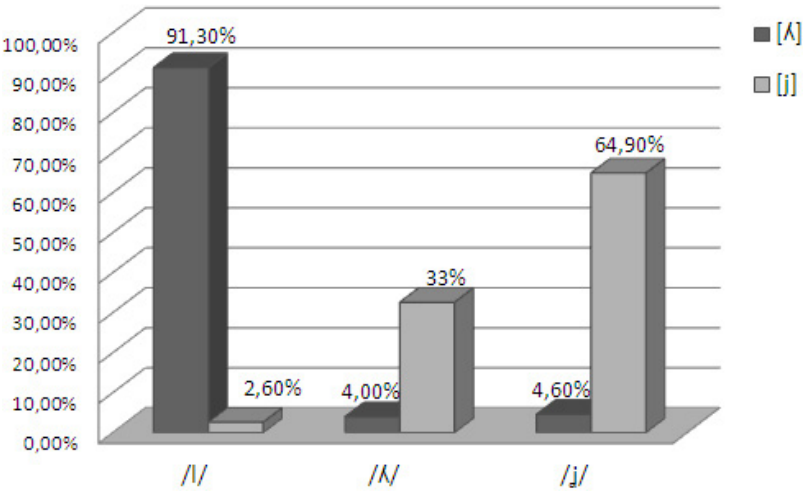

En la prueba 3 no se han podido aplicar pruebas estadísticas que den cuenta de la relación entre realización fonética y categoría fónica percibida puesto que el input respondía a una única realización y ello implica que la variable independiente es, en realidad, una constante.

\subsubsection{Influencia del acento}

En cuanto al acento, se observa que los estímulos tienden a reconocerse mejor en sílaba tónica $(74,4 \%$, $n=160)$ que en átona $(61,1 \%, n=360)$. Las confusiones con la lateral, por lo tanto, son más habituales en contexto inacentuado (38,9\% frente a 25,6 \% en posición tónica). Este comportamiento se hace más evidente todavía al analizar los errores obtenidos en uno y otro contexto: un $77,3 \%$ del total de 181 casos de confusión se localizan en sílaba átona, tal como se resume gráficamente en la Figura 6 , mientras que en posición acentuada ni siquiera llegan al $25 \%$.

Tabla 10. Número de casos de identificaciones exitosas en función del acento en la prueba 3 . Se han sombreado los resultados predominantes.

\begin{tabular}{|l|c|c|}
\hline \multirow{2}{*}{} & \multicolumn{2}{|c|}{$[\mathrm{j}]$} \\
\cline { 2 - 3 } & $/ \mathrm{j} /$ & $/ K /$ \\
\hline \multirow{2}{*}{ síl. tónica } & 119 & 41 \\
$(74,4 \%)$ & $(25,6 \%)$ \\
\hline síl. átona & 220 & 140 \\
$(61,1 \%)$ & $(38,9 \%)$ \\
\hline Total casos: & \multicolumn{2}{|c|}{520} \\
\hline
\end{tabular}

Figura 6. Gráfico de barras que muestra el porcentaje de errores de identificación en función del acento en la prueba 3.

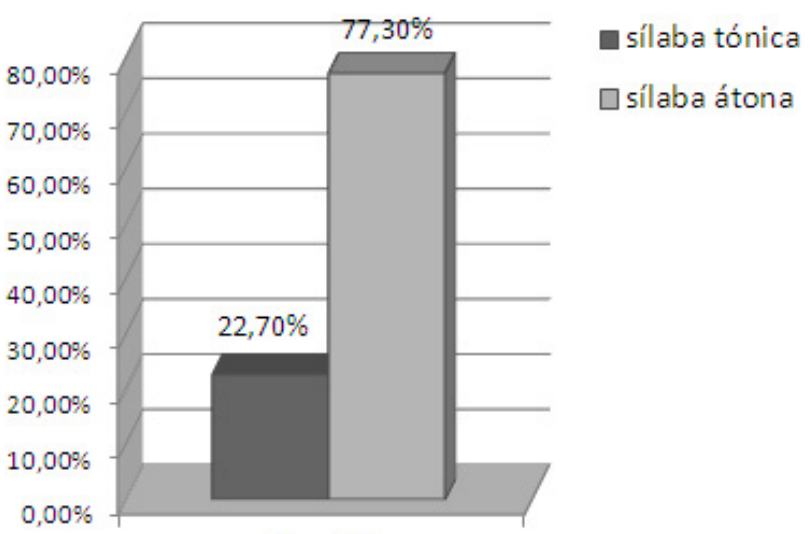

$[j]>/ N$

\subsubsection{Influencia de las vocales adyacentes}

El examen de los errores de identificación en función del contexto vocálico permite observar que estos se concentran principalmente en secuencias cuya primera vocal corresponde a una palatal (50,8 \% de las confusiones), al igual que en la prueba 2 (cf. Tabla 11). Si a estos casos se añaden aquellos que incluyen una vocal palatal tras la consonante (es decir, 135 ejemplos), se advierte que en el $74,5 \%$ de los errores de identificación intervienen elementos palatales.

Asimismo, es interesante notar que la cifra de confusiones en contexto palatal también es invariablemente mayor en sílaba átona que en tónica, tal como ocurría en la prueba 2: 74 ejemplos si se trata de la vocal precedente ( $80,4 \%$ de los casos en esta clase de contexto) y 25 si es 
la que sigue a la consonante. En consecuencia, los datos parecen señalar que un contexto palatal y átono debería facilitar las confusiones.

Tabla 11. Número de errores de discriminación de [j] en función del contexto vocálico y del acento en la prueba 3 . Se han sombreado los resultados predominantes. Los porcentajes se dan en relación al número global de errores.

\begin{tabular}{|c|c|c|}
\hline \multirow[b]{2}{*}{ contexto } & \multicolumn{2}{|c|}{$[\mathrm{j}] \rightarrow \mid \mathrm{K} /$} \\
\hline & síl. tónica & síl. átona \\
\hline$\left[\mathrm{V}_{\mathrm{pal}-} \mathrm{V}_{\mathrm{pal}}\right]$ & - & - \\
\hline$\left[\mathrm{V}_{\mathrm{pal}}-\mathrm{V}_{\mathrm{centr}}\right]$ & 12 & 44 \\
\hline$\left[\mathrm{V}_{\mathrm{pal}-} \mathrm{V}_{\mathrm{vel}}\right]$ & 6 & 30 \\
\hline Total casos: & \multicolumn{2}{|c|}{$92(50,8 \%)$} \\
\hline$\left[\mathrm{V}_{\mathrm{centr}-}-\mathrm{V}_{\mathrm{pal}}\right]$ & 14 & 17 \\
\hline$\left[\mathrm{V}_{\text {centr }-} \mathrm{V}_{\text {centr }}\right]$ & 5 & 7 \\
\hline$\left[\mathrm{V}_{\text {centr }-} \mathrm{V}_{\mathrm{vel}}\right]$ & - & - \\
\hline Total casos: & \multicolumn{2}{|c|}{$43(23,7 \%)$} \\
\hline$\left[\mathrm{V}_{\mathrm{vel}-} \mathrm{V}_{\mathrm{pal}}\right]$ & 4 & 8 \\
\hline$\left[\mathrm{V}_{\mathrm{vel}-} \mathrm{V}_{\text {centr }}\right]$ & - & 31 \\
\hline$\left[\mathrm{V}_{\left.\mathrm{vel}-\mathrm{V}_{\mathrm{vel}}\right]}\right]$ & - & 3 \\
\hline Total casos: & \multicolumn{2}{|c|}{$46(25,4 \%)$} \\
\hline TOTAL GLOBAL: & \multicolumn{2}{|c|}{$n=181 / 540$} \\
\hline
\end{tabular}

\section{DISCUSIÓN}

La comparación de los resultados obtenidos en las diferentes pruebas no deja de arrojar datos interesantes. Lo primero que debe analizarse es la diferencia en los porcentajes de aciertos y errores en las pruebas practicadas.

En efecto, como se observaba en el $\S 3.1$, el test 1 venía a demostrar que los jueces discriminaban perfectamente entre tres categorías fónicas que parecían netamente diferenciadas: $/ 1 /, / \mathrm{K} / \mathrm{y} / \mathrm{j} /$. No obstante, cabe recordar que la distancia perceptiva entre las dos últimas era menor que entre /1/ y cada una de ellas; es decir, la lateral alveolar se revela como un elemento menos susceptible de ser confundido (de hecho, es el que presenta un porcentaje de aciertos mayor, con un $94 \%$ de casos correctamente identificados). Por lo tanto, esta prueba inicial que actuaba como control también ha servido para dibujar un primer esbozo de la proximidad perceptiva entre los segmentos estudiados. Eso sí, hay que recordar que esta primera toma de contacto responde a la configuración del sistema fonológico del catalán, ya que los estímulos proceden de un locutor catalanohablante que, aunque esté produciendo un discurso en español, puede haber articulado estos segmentos según los parámetros propios de su lengua materna. Pese a todo, esta información resulta valiosa para mostrar la situación "ideal" en un escenario de distinción entre lateral palatal y aproximante palatal.
Lo interesante, a partir de ahí, es contrastar estos datos con los resultados de las pruebas 2 y 3 . Lo primero que cabe constatar es que el nivel de confusiones aumenta tanto en la 2 como en la 3 respecto a la 1 , tal como puede observarse en la Figura 7.

Figura 7. Tabla con los porcentajes de aciertos y errores de identificación en cada prueba y gráfico de líneas que muestra el volumen de errores de discriminación en cada prueba y para cada realización acústica. Se han sombreado los porcentajes de aciertos.

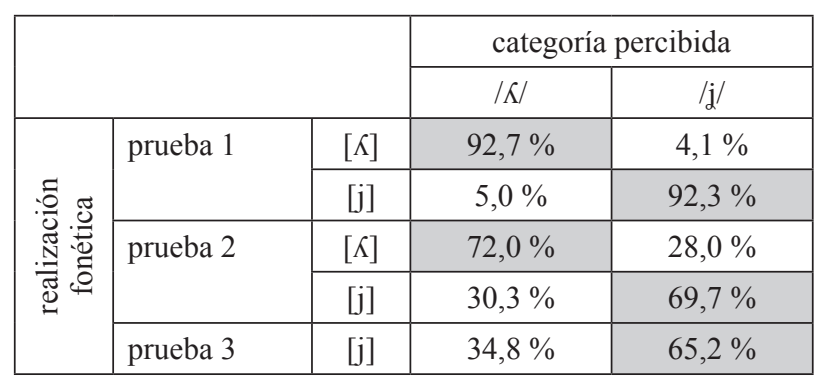
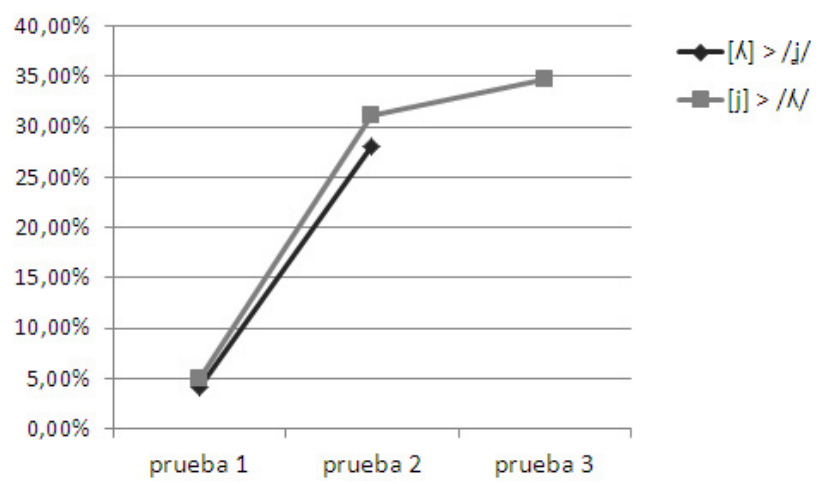

En efecto, los aciertos disminuyen (en ningún caso llegan al $90 \%$ inicial) y los errores llegan a suponer un tercio de los casos. Esto implica que, en un volumen importante de estímulos, la diferencia entre lateral palatal y aproximante palatal, que parecía clara en la prueba 1 (menos de un $10 \%$ de fallos), queda lo suficientemente difuminada como para inducir a error. Además, aunque los valores para la prueba 2 y la 3 no son significativamente diferentes, sí se advierte un ligero incremento en los casos de confusión en esta última. Esto conduce a pensar que la distancia perceptiva entre la lateral y la aproximante se reduce gradualmente desde los valores propios de un sistema netamente distinguidor (prueba 1) a uno en el que se dan vacilaciones: los cálculos de distancia perceptiva en la prueba 2 muestran, efectivamente, que la similitud entre ambos fonos es mayor $\mathrm{y}$, aunque estos cálculos no se han podido efectuar en la prueba 3 por falta de un input lateral palatal con el que comparar, cabe suponer que, si se pueden dar ocurrencias de identificación de la aproximante con un elemento palatal es porque los jueces, que son distinguidores, no pueden discernir fácilmente entre ambas categorías. 
Figura 8. Mapa de distancia perceptiva de los segmentos [1], $[K]$ y $[j]$ del catalán (en gris) y $[K]$ y $[j]$ del español (en negro), a partir de los datos de las matrices de confusión de las pruebas 1 y 2 .

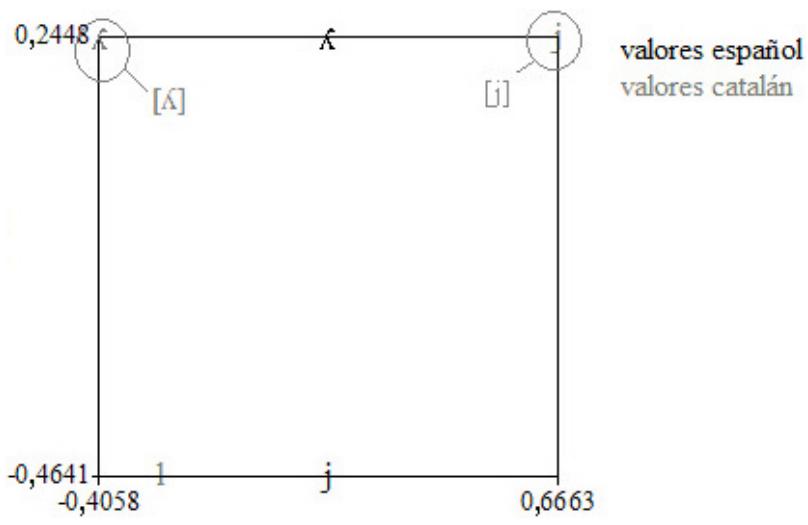

La Figura 8 reproduce el mapa de distancia perceptiva entre las diversas categorías para el español y el catalán. Gracias a la superposición de los valores para ambos sistemas se observa un fenómeno que puede ayudar a entender los resultados obtenidos. Como puede notarse, la lateral palatal del español (en negro) se encuentra en un espacio intermedio entre la lateral palatal y la aproximante palatal del catalán (en gris). En cambio, la aproximante palatal del español se sitúa a mayor distancia de los demás elementos. Estos resultados sugieren que lateral palatal y aproximante palatal del catalán y del español no son exactamente equivalentes, al menos en el nivel perceptivo, puesto que no ocupan el mismo espacio. Esto explicaría que los jueces, catalanohablantes, incurrieran en confusiones al identificar los segmentos propios del español. De hecho, este hallazgo es consistente con Recasens (2013, pp. 10-15), quien explica, desde un punto de vista articulatorio, que las lenguas que estudia en su artículo ${ }^{16}$ «may favor patterns involving both dental contact $[\ldots]$ or not» en la articulación de $[K]$ (p. 10), es decir, que el grado de constricción y el punto de articulación pueden diferir en función del sistema. De hecho, aunque Kochetov y Colantoni (2011) se centran en la descripción de las consonantes coronales del español en diversos dialectos, al estudiar el habla de un locutor madrileño, destacan que «the coronal consonants produced by the Peninsular speaker are relatively poorly differentiated in place, given the overall front realization of most articulations» (p. 332), lo que les resulta chocante respecto a las otras variedades estudiadas (cubano y argentino). Esto pone de manifiesto que puede haber diferencias incluso a nivel dialectal, dentro de un mismo sistema. En nuestro caso, el locutor de la prueba 2 es precisamente centropeninsular, con lo que no sería descabellado pen- sar en una articulación como la descrita por estos autores, que podría dar pie a confusiones debidas a la pobreza en la diferenciación de los estímulos y su proximidad con los valores propios de los de otro sistema. Entraríamos aquí en lo que Colantoni (2008) denomina "microvariación", es decir, estímulos de una L2 que son similares a categorías de la L1 y que pueden ser asimiladas a estas sin ser exactamente equivalentes. Eso hace que puedan ser reconocidas como iguales. Estas ideas casan con lo establecido por Flemming (2004, p. 238), quien defiende que los estímulos se conciben como colocados en un espacio multidimensional de semejanza en el que la distancia entre ellos está relacionada con la posibilidad de confusión; en otras palabras, cuanto más próximos se encuentren en ese espacio, más posibilidades habrá de que puedan ser confundidos.

$\mathrm{Si}$ las confusiones antes comentadas, muy probablemente debidas a la proximidad perceptiva de las categorías que deberían contrastar, se dan con hablantes que en principio tienen clara la diferencia, no sería descabellado pensar que esta confusión pueda darse en mayor medida en castellanohablantes, dado que la distancia perceptiva entre $[\Lambda]$ y $[\mathrm{j}]$ del español, como se ha visto, es menor que para el catalán.

Figura 9. Porcentaje de errores de identificación del estímulo en función del acento y del contexto vocálico en las pruebas 2 y 3 .

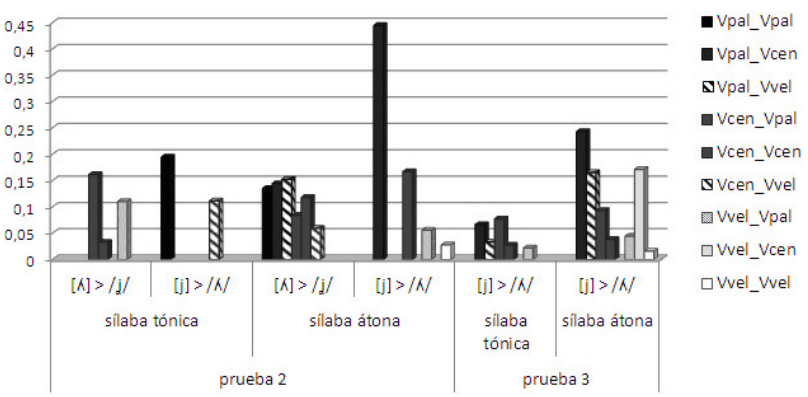

Otro aspecto que no cabe desdeñar son las confusiones, puesto que pueden aportar información importante acerca de las circunstancias en las que son más probables. En la Figura 9 se presentan, sintetizados, los datos referentes al análisis de los errores. Lo primero que cabe destacar es que, tanto en la prueba 2 como en la 3 , el volumen de los mismos es menor en sílaba tónica: el acento, por lo tanto, parece incidir en los fallos de identificación, que se dan de forma bastante generalizada en posición inacentuada. Este hecho parece lógico si se tiene en cuenta que un contexto átono favorece la hipoarticulación de los segmentos (cf. Lindblom, 1990a) y, en consecuencia, los fenómenos de relajación (entre ellos

\footnotetext{
${ }^{16}$ Se tienen en cuenta lenguas africanas (ibibio, ngwo, suto, zulú), asiáticas (caucásicas: japonés, abjasio; sino-tibetana: chino), australianas (arrente, warlpiri), austronésica (malgache) y europeas (célticas: irlandés; germánicas: inglés, alemán, islandés, sueco; románicas: catalán, francés, italiano, occitano, portugués, retorromance, rumano, español; eslavas: checo, polaco, ruso, eslovaco; y uránicas: húngaro).
} 
los de tipo coarticulatorio), lo que supone que el output generado puede no resultar diáfano desde un punto de vista perceptivo ${ }^{17}$.

Otra cuestión importante que debe comentarse atendiendo a la información que se desprende del mismo gráfico es el predominio de las confusiones de [j] con $/ K /$, especialmente entre vocales palatales o entre vocal palatal y vocal central (las barras en color más oscuro). Sin embargo, se observa también que prácticamente no hay errores entre vocales velares. En cualquier caso, parece que la presencia de un segmento vocálico palatal se asocia a la aparición de confusiones. La explicación no resulta extraña si se toman en consideración factores de tipo coarticulatorio, habituales en posición inacentuada: la presencia de una vocal palatal, particularmente [i], supone una configuración del tracto vocal similar a la de $[\mathrm{j}]^{18}$, por lo que podría esperarse una producción tendente a una aproximante más que a una lateral, que requiere una oclusión en la parte central de la cavidad oral, esto es, un mayor grado de constricción y, por lo tanto, de esfuerzo en la articulación. Desde esta perspectiva, cuando menos, se puede comprender la confusión. No obstante, es importante no perder de vista que, como se ha comentado en la Sección 2, los estímulos proporcionados respondían a las características acústicas propias de cada una de las categorías, $[K]$ y [j], por lo que se trata, en principio, de sonidos diferentes. En consecuencia, habría que entender que el acento y los elementos palatales adyacentes constituyen índices que influyen en una reinterpretación de la categoría perceptiva de dicho sonido. Efectivamente, Flemming (2004, p. 356) admite que, en un contexto dado, puede ser complicado detectar los contrastes entre estímulos. Para dar cuenta de ello, argumenta que la realización de los sonidos está gobernada por el principio del mínimo esfuerzo, de modo que las diferencias entre los fonos pueden llegar a ser difíciles de advertir porque la realización con menor esfuerzo perteneciente una categoría fónica acaba siendo similar a otros sonidos que deberían contrastar con ella. Así pues, se entiende que el esfuerzo articulatorio ha de estar necesariamente implicado en la consecución de los índices perceptivos, los cuales, en definitiva, resultan altamente dependientes del contexto (p. 243).

Estas constataciones harían pensar en una justificación del cambio bastante lógica: en un contexto de hipoarticulación, en el que pueda darse coarticulación con vocales adyacentes palatales, parece coherente que se tienda a identificar la consonante con un elemento palatal no lateral. Sin embargo, hay que tener en cuenta la dirección de las confusiones y esta cuestión ofrece un panora- ma quizá inesperado, si se toma como referencia el rumbo que ha seguido el cambio yeísta. Como se ha observado ya a partir de los datos de la Figura 7 (y que se reproducen aquí en la Tabla 12), las tasas de identificaciones correctas son invariablemente superiores para $[K]$ en todos los test en que hay estímulos de esta clase; en cambio, el porcentaje de errores en la identificación de $[\Lambda]$ y de [j] está bastante equilibrado en todas las pruebas practicadas salvo, claro está, en la tercera. Con todo, el mayor volumen de errores (aunque la diferencia sea leve) se detecta en los casos en que el input es una aproximante: comparativamente, suele haber más ejemplos de confusión de [j] con $/ K /$ que en el sentido contrario (suponen más de un $30 \%$ en las pruebas 2 y 3). En la prueba 3, precisamente, el número de ocurrencias categorizadas como lateral palatal es el más alto $(34,8 \%)$. Esta tendencia sorprende, máxime sabiendo que la neutralización se da por la desfonologización progresiva de la lateral en favor de la aproximante, por lo que quizás sería esperable que las confusiones hubieran tomado una dirección opuesta.

Tabla 12. Porcentaje de aciertos y confusiones en cada una de las pruebas practicadas para las realizaciones $[K]$ y $[j]$. Cf. Figura 7.

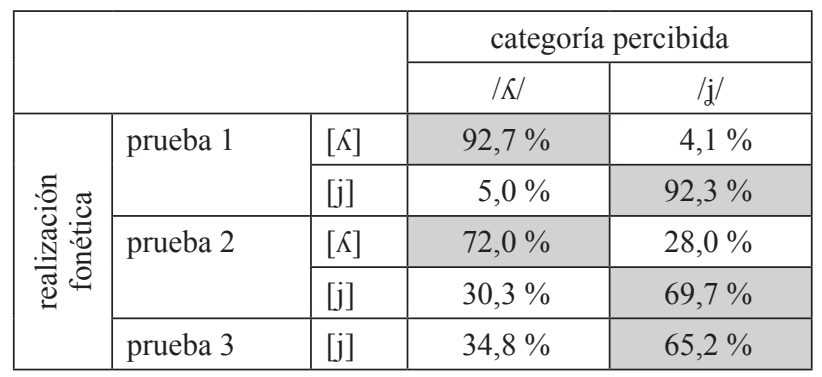

Una forma de explicarlo sería que la solución más frecuente en el sistema fonológico del español es la aproximante (por el volumen de contextos y de voces que la incluyen); de este modo, en caso de ambigüedad, los hablantes podrían optar por interpretar la variante más habitual frente a la que consideran menos común. Esto encajaría con la explicación del cambio por el procedimiento combinado de azar y selección, en la terminología de Blevins (2004): ante una señal fonológicamente ambigua, los receptores reinterpretan el estímulo recibido y lo reanalizan como una categoría diferente de la de quien ha proporcionado el input y, en el caso de que esa señal se produjera en una situación de variación fónica, el interlocutor seleccionaría la opción que considerase más fre-

\footnotetext{
${ }_{17}$ De hecho, Marrero Aguiar (2008) destaca que las posiciones que favorecen la tendencia a la relajación (esto es, a la hipoarticulación) dificultan la percepción (p. 225). En este sentido, Stevens (2005) incluye entre los factores que pueden debilitar los rasgos distintivos que debe identificar un receptor determinados aspectos de la prosodia, entre ellos el acento o la prominencia de la sílaba en la palabra (pp. 134-135).

${ }^{18}$ Pese a que Recasens (2013) determina que la aproximante (que él denomina "glide”) presenta una constricción más anterior que la vocal ("an alveolar or alveolopalatal constriction occurs more often for the glide [...] while a purely palatal constriction takes place somewhat more frequently for the vowel") (pp. 14-15) el hecho de que ninguna de las dos presente una oclusión en la parte central de la cavidad oral las distingue de la lateral.
} 
cuente $(\S 2.2)$. En el yeísmo, sabemos que se puede dar variación en las formas en que se produce la consonante: sin ir más lejos, Moreno Fernández (2004, pp. 984-985) indica que, en la segunda y tercera fases del cambio, se produce precisamente una amplia variación en la forma que puede presentar el fonema $/ K /$, algunos de cuyos alófonos coincidirían con los del fonema palatal no lateral. Un hablante, en esta situación, puede producir un segmento lateral palatal que, por contexto, por la existencia de ruidos en la interacción comunicativa, no se perciba como tal y se reinterprete como aproximante. $\mathrm{O}$ al revés: que se emita un elemento no lateral que, por contexto (incluso léxico), pueda ser identificado como $/ K /$.

En este sentido, la concepción del cambio de Bybee (1999) es bastante explicativa. Esta autora afirma que en los fenómenos de cambio fónico entran en juego la relación de la fonología y la fonética con otros niveles de la lengua, como el léxico y la morfología. De hecho, insiste en que «the phonetic percepts that are input and output of the grammar are related in a very direct fashion to the meanings they convey and the contexts in which they occur» (p. 222). Un elemento que considera crucial en el desarrollo de los cambios es la frecuencia de uso, algo que también reconoce Blevins (2004): los elementos más habituales serán los más productivos, los que más probablemente van a aplicar sus patrones léxicos, morfológicos y fónicos sobre otros menos recurrentes que, de algún modo, van a absorber sus rasgos más prominentes. Desde este punto de vista, no sería inverosímil que, en caso de vacilación, los hablantes optaran por un patrón fónico de mayor uso, en nuestro caso [j], frente a $[K]$. Alarcos Llorach denunciaba que la oposición no era productiva $(1965, \text { p. } 279)^{19}$ y que existían pares mínimos muy escasos que pudieran justificar su mantenimiento (1994, p. $35)$. De hecho, comentaba que «el momento en que se produzca una confusión que impida la percepción de las relaciones formales originarias del sistema», este se modificará para evitarla (1965, p. 115). Sin llegar a una postura teleológica como la suya para la explicación del cambio, sí es cierto que tal afirmación viene a apoyar, en cierto modo, lo que acabamos de comentar.

El cambio fónico, como es sabido, se da en el momento en que existe variación y esta afecta a la interpretación de la señal, momento en que puede producirse una reorganización de los elementos que forman el sistema; es decir, además de la variación fonética, para que podamos hablar de cambio se requiere un reanálisis del input por parte del receptor (cf. Blevins, 2004; u Ohala, 1981, 2012). Sin este segundo paso, la evolución no puede prosperar, simplemente porque no puede expandirse. Los resultados obtenidos dibujan un contexto propicio para que se pueda producir esta segunda fase: se sabía ya de la existencia de una importante cantidad de soluciones para $/ K /$, la más habitual de las cuales ha dejado de ser $[K]^{20} ; \sin$ embargo, no se había prestado atención a la necesaria intervención del interlocutor ante tal situación. Lo que se puede advertir a raíz de la investigación llevada a cabo es que, en realidad, los receptores de la señal, incluso ante estímulos claros, confunden los segmentos y llegan a interpretarlos de forma diferente a la esperada: la categorización perceptiva no resulta unívoca (no con un volumen de errores del $30 \%$, aproximadamente, tanto para $[K]$ como para [j]), lo que señala que se trata de elementos que se ubican en un territorio límite entre categorías en ese espacio multidimensional de semejanza que describe Flemming (2004). Estas condiciones son favorables para que el sistema fonológico se vea modificado y, en consecuencia, se verifique la progresiva desfonologización del fono menos frecuente (o productivo, si se quiere una terminología más cercana a autores como Alarcos Llorach) y más costoso de producir. Los datos permiten comenzar a apuntar a la figura del oyente, habitualmente olvidada en el caso del yeísmo, como una de las claves del inicio y el avance del cambio.

\section{CONCLUSIONES}

A la vista de los datos obtenidos y las reflexiones realizadas, llegamos a la conclusión de que, en efecto, el yeísmo como cambio puede tener una base perceptiva que complemente las explicaciones tradicionales, habitualmente cimentadas sobre argumentos meramente articulatorios. La existencia de confusión en la discriminación de los estímulos correspondientes a $[K]$ y a $[j]$ por parte de jueces que son capaces de distinguirlos en su lengua materna (catalán) apunta a que estos sonidos pueden resultar ambiguos a nivel perceptivo, especialmente en sílaba átona y en contacto con vocales palatales, ya que estos contextos parecen favorecer los errores en su interpretación.

De todos modos, esta investigación ha planteado nuevas incógnitas. En primer lugar, parece señalar que, desde un punto de vista perceptivo, $[K]$ y [j] no resultan exactamente equivalentes en catalán y en español, lo que probablemente implicaría que su articulación y la señal acústica que se deriva de ella tampoco han de ser coincidentes. Así pues, en estudios posteriores habrá que abordar el análisis de las características acústicas de ambos elementos: ya que la percepción se basa directamente en los estímulos acústicos que llegan al oído, se considera importante esclarecer cuáles son los rasgos que han de permitir discriminar ambos segmentos y si son equivalentes en los dos sistemas.

Otra cuestión relevante es que, precisamente porque el yeísmo ha alcanzado un grado de expansión muy importante, el estudio perceptivo presentado ha recurrido a jueces catalanohablantes, con la premisa de que mante-

\footnotetext{
${ }^{19}$ Alarcos Llorach (1965) afirma, literalmente, que «evidentemente no tiene un rendimiento funcional muy amplio» (p. 279).

${ }^{20}$ Este sonido ha podido ser detectado como alófono de /1/ en ciertos contextos, más que como realización de un fonema lateral palatal (cf. Rost Bagudanch, 2011, en prensa).
} 
nían la oposición fonológica. Como se ha indicado, estos jueces cometen errores en la identificación de los estímulos en lengua española, lo que sugeriría que la confusión puede tener un origen perceptivo. Sin embargo, se ha advertido que la distancia perceptiva entre las categorías fónicas del catalán y las del español no eran equivalentes. Por lo tanto, habría que tomar con cierta cautela los resultados obtenidos a la espera de administrar pruebas perceptivas a hablantes nativos de español distinguidores. Estos resultados, pese a tener que ser considerados con cierta precaución, tienen el valor de ser una primera aproximación a la explicación del cambio en marcha y pueden reproducir lo ocurrido en las primeras fases del fenómeno yeísta, cuando hablantes distinguidores (como nuestros jueces) se enfrentan a la existencia de variación y pueden reanalizar la señal percibida de forma diferente al locutor que se la ha proporcionado. Por lo tanto, permite componer una primera "foto fija" en la explicación del proceso de desfonologización de $/ K /$.

Como no podría ser de otro modo, la conclusión principal a la que se llega a partir de este trabajo es, simplemente, que falta trabajar mucho en la vertiente perceptiva y acústica de la confusión yeísta con el fin de poder aportar una justificación completa y eficaz que sirva para la comprensión del fenómeno.

\section{REFERENCIAS}

Alarcos Llorach, E. (1965). Fonología española (4. ${ }^{\mathrm{a}}$ ed.). Madrid: Gredos.

Alarcos Llorach, E. (1994). Gramática de la lengua española. Madrid: Espasa-Calpe, Real Academia Española de la Lengua.

Alcina Franch, J., \& Blecua, J. M. (1975). Gramática española. Barcelona: Ariel.

Blevins, J. (2004). Evolutionary Phonology. Cambridge: Cambridge University Press. http://dx.doi.org/10.1017/CBO9780511486357

Bybee, J. L. (1999). Usage-based Phonology. In M. Darnell, E. A. Moravcsik, F. Newmeyer, M. Noonan, \& K. Wheatley (Eds.), Functionalism and formalism in linguistics, volume I: General papers (pp. 211-242). Amsterdam: John Benjamins.

Colantoni, L. (2008). Variación micro y macro fonética en español. Estudios de Fonética Experimental, XVII, 65-104.

Coloma, G. (2012). Caracterización fonética de las variedades regionales del español y propuesta de transcripción simplificada. Revista de Filología Románica, 28, 11-27. http://dx.doi. org/10.5209/rev RFRM.2011.v28.37217

Fernández Planas, A. M. (2001). Estudio electropalatográfico de la coarticulación vocálica en estructuras VCV en castellano (tesis doctoral). Barcelona: Universitat de Barcelona. Disponible en http://www.tdx.cat/handle/10803/2094.

Fernández Trinidad, M. (2010). Variaciones fonéticas del yeísmo: Un estudio acústico en mujeres rioplatenses. Estudios de Fonética Experimental, XIX, 263-292.

Flemming, E. (2004). Contrast and perceptual distinctiveness. In B. Hayes, R. Kirchner, \& D. Steriade (Eds.), Phonetically based phonology (pp. 232-276). Cambridge, UK: Cambridge University Press. http://dx.doi.org/10.1017/CBO9780511486401.008

García Mouton, P., \& Molina Martos, I. (2012). The / $/ \mathrm{K} / \mathrm{/j} / \mathrm{merger}$ (yeísmo) in Central Spain: Advances since the ALPI. Dialectologia, III, 23-42. Disponible en http://www.raco.cat/index.php/ Dialectologia/index

Gómez, R., \& Molina Martos, I. (Eds.). (2013). Variación yeísta en el mundo hispánico. Madrid: Iberoamericana/Vervuert.
Hernando Cuadrado, L. A. (2001). Sobre el origen y situación actual del yeísmo en Hispanoamérica. Studia Carande: Revista de Ciencias Sociales y Jurídicas, 6, 449-460.

Hualde, J. I. (2005). The sounds of Spanish. Cambridge, UK: Cambridge University Press.

Johnson, K. (2003). Acoustic and auditory phonetics (2nd ed.). Malden, MA: Blackwell.

Kochetov, A., \& Colantoni, L. (2011). Coronal place contrasts in Argentine and Cuban Spanish: An electropalatographic study. Journal of the International Phonetic Association, 41(3), 313342. http://dx.doi.org/10.1017/S0025100311000338

Ladefoged, P., \& Maddieson, I. (1996). The Sounds of the world languages. Oxford: Blackwell.

Lindblom, B. (1990a). Explaining phonetic variation: A sketch of the H\&H Theory. In W. J. Hardcastle \& A. Marchal (Eds.), Speech production and speech modelling (pp. 403-439). Dordrecht: Kluwer Academic. http://dx.doi.org/10.1007/978-94-009-2037-8 16

Lindblom, B. (1990b). Models of phonetic variation and selection. PERILUS, XI, 65-100.

Marrero Aguiar, V. (2008). La fonética perceptiva: trascendencia lingüística de mecanismos neuropsicofisiológicos. Estudios de Fonética Experimental, XVII, 207-245.

Martínez Celdrán, E. (2004). Problems in the classification of approximants. Journal of the Acoustic Society of America, 34(2), 201-210.

Martínez Celdrán, E., \& Fernández Planas, A. M. (2002). Características fonéticas de la africada palatal sonora del español. In M. T. Díaz Hormigo (Ed.), IV Congreso de Lingüística General: Cádiz, del 3 al 6 de abril de 2000 (pp. 1751-1761). Cádiz: Servicio de Publicaciones de la Universidad de Cádiz y Servicio de Publicaciones de la Universidad de Alcalá.

Martínez Celdrán, E., \& Fernández Planas, A. M. (2007). Manual de fonética española: Articulaciones y sonidos del español. Barcelona: Ariel.

Molina Martos, I. (2006). Innovación y difusión del cambio lingüístico en Madrid. Revista de Filología, LXXXVI(1), 127-149. http://dx.doi.org/10.3989/rfe.2006.v86.i1.5

Moreno Fernández, F. (2004). Cambios vivos en el plano fónico del español: Variación dialectal y sociolingüística. In R. Cano Aguilar (Coord.), Historia de la lengua española (pp. 9731010). Barcelona: Ariel.

Navarro Tomás, T. (1964). Nuevos datos sobre el yeísmo en España. Thesaurus: Boletín del Instituto Caro y Cuervo, XIX(1), $1-17$.

Ohala, J. J. (1981). The listener as a source of sound change. In C. S. Masek, R. A. Hendrick, \& M. F. Miller (Eds.), Papers from the parasession on language and behavior (pp. 178-203). Chicago: Chicago Linguistic Society.

Ohala, J. J. (1996). Speech perception is hearing sounds, not tongues. Journal of the Acoustic Society of America, 99(3), 17181725. http://dx.doi.org/10.1121/1.414696

Ohala, J. J. (2012). The listener as a source of sound change. An update. In M.-J. Solé \& D. Recasens (Eds.), The initiation of sound change. Perception, production, and social factors (pp. 21-35). Amsterdam: John Benjamins. http://dx.doi.org/10.1075/ cilt.323.05oha

Quesada Pacheco, M. Á. (Ed.) (2010). El español hablado en América Central. Nivel fonético. Madrid: Iberoamericana/Vervuert.

Quilis, A. (1999). Tratado de fonología y fonética españolas (2. ${ }^{a}$ ed.). Madrid: Gredos.

Quilis, A., Esgueva, M., Gutiérrez Araus, M. L., \& Cantarero, M. (1979). Características acústicas de las consonantes laterales españolas. Lingüística Española Actual, 1, 233-343.

Real Academia Española. (2011). Nueva gramática de la lengua española. Fonética y fonología. Madrid: Espasa-Calpe.

Recasens, D. (1991). Fonetica descriptiva del català: assaig de caracterització de la pronúncia del vocalisme $i$ del consonantisme del català al segle $X X$. Barcelona: Institut d'Estudis Catalans.

Recasens, D. (2013). On the articulatory classification of (alveolo)palatal consonants. Journal of the International Phonetic Association, 43(1), 1-22. http://dx.doi.org/10.1017/S0025100312000199 
Recasens, D., \& Espinosa, A. (2006). Articulatory, positional and contextual characteristics of palatal consonants: Evidence from Majorcan Catalan. Journal of Phonetics, 34(3), 295-318. http:// dx.doi.org/10.1016/j.wocn.2005.06.003

Rost Bagudanch, A. (2011). Variación en los procesos de palatalización de yod segunda (o cómo la sincronía permite la explicación de la diacronía) (tesis doctoral) Girona: Universitat de Girona. Disponible en http://www.tdx.cat/handle/10803/31860.

Rost Bagudanch, A. (2013). La transcripción fonética en estudios dialectales: Propuestas en el caso del yeísmo. Revista de Filología Española, 93(1), 165-192. http://dx.doi.org/10.3989/ rfe.2013.06
Rost Bagudanch, A. (2014). Una panorámica del yeísmo: ¿Un proceso acabado o en construcción? Revista Internacional de Lingüística Iberoamericana, XII, 1(23), 141-163.

Rost Bagudanch, A. (en prensa). Las laterales del español: ¿Un sistema con necesidad de reformas? Revista Española de Lingüística, 44(2).

Stevens, K. N. (2005). Features in speech perception and lexical access. In D. B. Pisoni \& R. E. Remez (Eds.), The handbook of speech perception (pp. 125-155). Oxford: Blackwell. http:// dx.doi.org/10.1002/9780470757024.ch6

\section{ANEXOS}

\section{A1. Estímulos empleados en la prueba 1}

\begin{tabular}{|c|c|}
\hline estímulo & palabra de procedencia \\
\hline \multicolumn{2}{|l|}{$/ 1 /$} \\
\hline ['ale] & cale \\
\hline \multirow[t]{2}{*}{ ['ala] } & hala \\
\hline & pala \\
\hline ['alo] & exhalo \\
\hline$\left[a^{\prime} 10\right]$ & alófono \\
\hline \multirow[t]{3}{*}{ ['ola] } & ola \\
\hline & controla \\
\hline & amapola \\
\hline \multirow[t]{2}{*}{ ['olo] } & controlo \\
\hline & pipiolo \\
\hline ['ulo] & zulo \\
\hline \multicolumn{2}{|l|}{$/ K /$} \\
\hline$\left[\mathrm{a}^{\prime} \mathrm{Ke}\right]$ & hallé \\
\hline \multirow[t]{2}{*}[\mathrm{\prime}\mathrm{a}\wedge\mathrm{a}]{} & halla \\
\hline & caballa \\
\hline$\left[\mathrm{a}^{\prime} \mathrm{Ko}\right]$ & Mallorca \\
\hline \multirow[t]{3}{*}{ ['oKa] } & olla \\
\hline & ampolla \\
\hline & collado \\
\hline ['oKo] & cogollo \\
\hline ['uKa] & hulla \\
\hline \multirow[t]{2}{*}{ ['uKo] } & orgullo \\
\hline & perogrullo \\
\hline \multicolumn{2}{|l|}{$/ \mathrm{j} /$} \\
\hline [a'je] & ayer \\
\hline ['aja] & haya \\
\hline \multirow[t]{2}{*}{ [a'ja] } & cayado \\
\hline & payaso \\
\hline [a'jo] & mayor \\
\hline \multirow[t]{2}{*}{ ['oja] } & joya \\
\hline & boya \\
\hline ['ojo] & apoyo \\
\hline ['uja] & huya \\
\hline \multirow[t]{2}{*}{ ['ujo] } & huyo \\
\hline & cuyo \\
\hline
\end{tabular}

A2. Estímulos empleados en la prueba 2

\begin{tabular}{|c|c|}
\hline estímulo & palabra de procedencia \\
\hline \multicolumn{2}{|l|}{$/ K /$} \\
\hline$[\mathrm{i} K \mathrm{e}]$ & bachillerato \\
\hline \multirow[t]{4}{*}[\mathrm{i}\kappa\mathrm{a}]{} & Villavieja \\
\hline & morcilla \\
\hline & bombilla \\
\hline & bombillas \\
\hline \multirow[t]{3}{*}{ ['iKo] } & calzoncillos \\
\hline & dinerillo \\
\hline & pasillo \\
\hline$[\mathrm{e} \kappa \mathrm{a}]$ & que llamaban \\
\hline$[\mathrm{e} \kappa \mathrm{e}]$ & me llevaba \\
\hline ['eאo] & ellos (2) \\
\hline \multirow[t]{2}{*}[{}^{\prime}\mathrm{a}K\mathrm{e}]{} & calle \\
\hline & calles \\
\hline$\left[\mathrm{a}^{\prime} \kappa \mathrm{i}\right]$ & allí \\
\hline \multirow[t]{2}{*}[\mathrm{o}^{\prime}\mathrm{Ka}]{} & lo llaman \\
\hline & lo llamo \\
\hline \multirow[t]{2}{*}[\mathrm{o}K\mathrm{e}]{} & solo llegar \\
\hline & cuando llegamos \\
\hline \multicolumn{2}{|l|}{$/ \mathrm{j} /$} \\
\hline [e'je] & de Yeltes \\
\hline \multirow[t]{2}{*}{ ['aja] } & vayan \\
\hline & playa \\
\hline [a'jo] & mayor \\
\hline ['oje] & oye \\
\hline ['ojo] & apoyos \\
\hline
\end{tabular}




\section{A3. Estímulos empleados en la prueba 3}

\begin{tabular}{|c|c|}
\hline estímulo & palabra de procedencia \\
\hline \multicolumn{2}{|l|}{ /j/ } \\
\hline \multirow[t]{2}{*}{ ['ija] } & silla (2) \\
\hline & pantorrilla \\
\hline ['ijo] & tobillo \\
\hline [i'jo] & maravillosa \\
\hline [eja] & de llamar \\
\hline ['eja] & ella \\
\hline [e'ja] & castellana (2) \\
\hline ['ejo] & aquello \\
\hline ['aje] & calle (2) \\
\hline \multirow[t]{2}{*}[a^{\prime}j\mathrm{je}]{} & Vallés (2) \\
\hline & la Yeti \\
\hline ['aja] & Anaya \\
\hline [a'ja] & allá \\
\hline ['oja] & Troya (3) \\
\hline ['oje] & destroyer (2) \\
\hline [o'je $]$ & cuando llegue \\
\hline ['ojo] & desarrollo \\
\hline ['uja] & capulla \\
\hline ['ujo] & capullo \\
\hline
\end{tabular}

